\title{
ERRORS IN THE STUDY OF THE VARIATIONAL BEHAVIOR OF FUNCTIONS IN THE UNIVERSITY ENGINEERING STUDENTS
}

\author{
Alejandro Ecos Espino ${ }^{1}$, Joffré Huamán Núñez ${ }^{2}$, Braulio Barzola Moscoso², \\ Zoraida Manrique Chávez ${ }^{3}$, Alejandro Rumaja Alvitez ${ }^{4}$ and Oscar García Cajo ${ }^{5}$ \\ ${ }^{1}$ Universidad Nacional de Moquegua, Calle Ancash s $n$, Moquegua, Perú \\ ${ }^{2}$ Universidad Nacional Micaela Bastidas de Apurímac, Av. Garcilaso s/n. Abancay, Perú \\ ${ }^{3}$ Universidad Nacional Intercultural de la Amazonía, Av. Contamana s/n, Pucallpa, Perú \\ ${ }^{4}$ Universidad Nacional José Maria Arguedas, Jr. Juan F. Ramos, Andahuaylas, Perú \\ ${ }^{5}$ Universidad Nacional de Huancavelica, Av. Agricultura 319-321, Huancavelica, Perú
}

\begin{abstract}
The study of the variational behavior of functions constitutes an important element in the understanding of the change of phenomena in real life. His understanding is an essential axis in the mathematical training of university students, especially those who pursue engineering careers. This article presents the results of a study whose objective was to determine the mistakes made by engineering students about the variational behavior of functions. The Duval Semiotics Records Theory was taken as a reference and a questionnaire was prepared with questions about identification of regions of variability for " $x$ " and " $y$ "; regions of growth, decrease, stability, extreme values and, analysis and description of the behavior of the function. The evaluation of the answers was done in a quantitative-qualitative way, from an exploratory and descriptive perspective, with 100 students participating in the civil engineering career. The results indicate that students do not make a real reflection on the variational behavior in intervals of the variables or in a global way. They have difficulty discriminating between the behavior of the function and the location of the function. They present cognitive difficulties that do not allow them to make an adequate conversion from one register to the other. Errors related to mathematical language were found, to the limitations to obtain spatial information, to establish erroneous inferences and to the inadequate development of previous knowledge, which does not allow them to properly evaluate the variational behavior of the functions.
\end{abstract}

\section{KEYWORDS}

Errors, Functions, Variational Behavior

\section{INTRODUCTION}

Within the development of advanced mathematical thinking, the traditional teaching model has not been effective and focuses its actions on the understanding of algorithms for mechanical resolution of certain type exercises, generating difficulties in the adequate understanding of concepts and methods of thinking that are the center of this mathematic field (Artigue, 1995). Students can calculate, limite, derive or integrate without being able to assign a broader meaning to the notions involved in their understanding. (Cantoral, 2013).

Our experience working with university students, reflect the previous statements. Students prefer to act mechanically, restricting their work to the application of known formulas to find immediate results and to the algorithmic management of the variables that are part of a mathematical model, without questioning the type of dependence that exists between them and without really analyze the behavior of these variables. For the analysis of the variational behavior of the variables, the concept of function plays an important role, so the mistakes that are made in the study of this concept constitute an important input to propose teaching strategies that guarantee their adequate learning within a context of variation and change.

However, the learning of this object was limited as a result of the various forms of presentation it has and the way it is approached within the classroom. This multiplicity of representations, as well as the different conceptions that this concept has, make it one of the most difficult to understand, which is strengthened when 
algorithmization and analytical methods are prioritized in the classroom, rather than the development of mathematician thinking skills (Farfan, 1992). Due to their own nature and their definition, functions are characterized because they serve to generate models to explain phenomena of reality, which are susceptible to change in different ways, consequently, understanding their behavior implies understanding how they change and how they are quantified these changes, which forces to change the discourse within the classroom and focus its teaching on procedures that give priority to variation and change. Therefore, within the Calculation courses, the analysis of the variation should be considered as the guiding axis of its development so that the mathematical objects that are addressed there serve to quantify, describe and predict the speed of the variation in phenomena of nature (Dolores, 2007). In this sense, the management of various graphic and algebraic resources that involve the concept of function, represent important indicators to evaluate their variation and the behavior of this variation.

Consequently, the development of skills related to variational thinking requires conceptual ruptures and changes in previous knowledge that the student possesses, which will generate the presence of obstacles and errors as a result of cognitive conflicts that will occur in reading and interpretation. of the behavior of the functions in their different representations (Dolores, 2004).

The error is considered today, as an indisputable component and present in the learning process. Therefore, it is necessary to carry out diagnoses in order to treat and discuss students' misconceptions and thus create learning spaces that allow them to readjust their ideas (Del Puerto, Minnaard and Seminara, 2006). Students' errors determine their learning from other related content, so that their identification and analysis generates important information about the way mathematical knowledge is constructed; constituting in this way an alternative so that students become aware of the need to overcome them and thus achieve true learning and the planning of activities where they can explain and make sense of their mistakes (Carrión, 2007; Engler, Gregorini, Müller, Vrancken and Hecklein, 2004).

Based on the aforementioned, the present study aimed to determine the mistakes that engineering students make when they have to analyze the variational behavior of functions, since this constitutes an important element in the understanding of the change of real-life phenomena and his understanding is essential axis in the mathematical formation of university students.

\section{THEORETICAL BASES}

\subsection{The Theory of Semiotic Records}

Various theoretical approaches describe the role of representation systems in the learning of mathematics, considering as hypotheses that the transformations between the systems of representation of mathematical objects can facilitate the emergence of such objects in students (Contreras and Font, 2002).

Duval (1998) considers that the semiotic representations of an object are absolutely necessary to be able to represent an idea or a mathematical object. They play an essential role in the development of mental representations, in the fulfillment of different cognitive functions and in the production of knowledge, increasing the subject's ability to think about that object and therefore his knowledge of it. This author means representation registration to a set of signs used to represent an idea or a mathematical object (Duval, 1998). In order for a semiotic system to be considered a representation register, it must have three fundamental characteristics: to be identifiable, to allow treatment, and finally, to enable conversion.

Mathematical activity is always based on some sequence of successive changes from one representation to another. The use of different representations for the same object increases the subject's ability to think about that object and therefore his knowledge of it. That is why it is important to keep in mind that there are always many possible representations of the same object. Each representation provides a different content according to the system used for its production, but always the object represented remains invariant (Duval, 2004).

The learning of mathematics is determined by the progressive coordination that can be made between different semiotic systems of representation, which requires discrimination and coordination of semiotic systems of representation to become able to transform any representation. (Duval, 2004)

Seeing concepts in multiple registers and from multiple perspectives allows students to better organize their knowledge. This is considered a cognitive condition necessary for learning (González, 2006). 


\subsection{Obstacles and Errors in Learning Mathematics}

The generation of knowledge is a process with interruptions, which arises from ruptures, imbalances and reconstructions of previous knowledge. These ruptures can be foreseen by studying the situations and behavior of the students (Brousseau, 1986).

Bachelard (1988) raised the notion of epistemological obstacle to explain the appearance of errors. It does not refer to difficulties that arise in a disorganized manner or that derive from the absence of knowledge, but rather to difficulties directly linked to the ways of considering knowledge or knowledge itself. An obstacle is expressed through errors that are not due to chance, but are linked between them by a common source, a way of knowing, a characteristic, coherent and even correct conception that has been successful in a whole domain of actions (Brousseau, 1986).

Recognizing that errors can be due to epistemological and didactic causes and not only cognitive type is a first step to find possible solutions. The most frequent errors are precisely the first two in such a way that they are frequently manifested at the time of manipulating a representation within the same system of representation, which is usually the algebraic one. Another error that usually occurs is the inappropriate choice of a semiotic system to solve a certain problem. (González, 2006).

Duval (2004) expresses that many of the students' difficulties can be described and explained as a lack of coordination of different representation records. Cognitive difficulties for conversion, determined by two main factors. The first is the non-congruence between two representation contents of the same object. The second is the non-reversibility of the conversion.

This work used as a frame of reference the classification of errors proposed by Abrate et al. (2006), which are set out below:

a) Errors due to mathematical language

b) Error is due to difficulties in obtaining spatial information

c) Errors due to incorrect inferences or associations

d) Errors due to the recovery of a previous scheme

e) Errors due to incorrect or accidental calculations

f) Possible errors due to deficiencies in the construction of prior knowledge

g) Errors due to lack of prior knowledge

\subsection{Variational Thinking}

Variational thinking can be described roughly as a dynamic way of thinking, which attempts to mentally produce systems that relate their internal form variables in such a way that they vary together in similar patterns to quantities of the same or different magnitudes in the trimmed threads of reality. (Vasco, 2006).

Cantoral (2013) states that this type of thinking includes the mathematics of change on the one hand and thought processes on the other; it implies the integration of the numerical domains, from the natural to the complex, concepts of variable, function, derivative and integral, as well as their symbolic representations, their properties and the domain of the elementary modeling of the phenomena of change.

The study of the concepts, procedures and methods that involve variation are integrated into different systems of graphic representation, tabular, verbal expressions, diagrams, symbolic expressions, particular and general examples, to allow, through them, the understanding of Mathematical concepts In this way, the situations that depend on the systematic study of the variation become significant, since it is obliged not only to express attitudes of observation and registration, but also to processes of treatment, coordination and conversion.

\section{METHOD}

The study carried out has a quantitative-qualitative research approach, as well as explanatory and descriptive. The population was made up of the entrants to the engineering careers of the three universities of the Province of Abancay in Perú. We worked with a non-probabilistic sample of an intentional type made up of 100 incoming students (66\% male and 34\% female) to the civil engineering career distributed as follows: 48 from the Universidad Nacional Micaela Bastidas de Apurímac (UNAMBA) of the of which 67\% were male and 
$33 \%$ female, 29 from the Universidad Tecnológica de los Andes (UTEA) of which 59\% were male and 41 were female and 23 from the Universidad Alas Peruanas (UAP) of which the $74 \%$ were male and $26 \%$ were female.

A questionnaire composed of 3 problematic situations constructed in the representation records was designed and validated: graphic, algebraic, verbal. The questions that made up these situations revolved around the variational behavior of the functions, whose indicators were the following: identification of regions of variability for both "x" and "y"; regions of growth, decrease, stabilization, extreme values as well as analysis and description of the behavior of the function.

Variance analysis of a factor was performed to identify differences between the means obtained by the groups. On the other hand, the analysis of the answers and the determination of the students' mistakes were carried out from a qualitative perspective, through a case study, in their exploratory and descriptive form.

\section{RESULTS}

The results obtained from the application of the research instrument to the sample of students chosen are presented below.

Table 1. Mean obtained by the groups

\begin{tabular}{lcc}
\hline \multicolumn{1}{c}{ Groups } & M & DE \\
\hline UNAMBA & 7.4375 & 4.1071 \\
UAP & 5.3043 & 0.8757 \\
UTEA & 5.3276 & 1.2121 \\
\hline
\end{tabular}

Within a scale of vigesimal evaluation, in Table 1 it was found that in all the study groups, the average performance achieved by the students is poor in relation to the study of the variational behavior of the functions. In general, this poor performance is a characteristic in the students of the 2 private universities where less dispersion is reflected. However, at the state university (UNAMBA), the greater dispersion of the results reflects the existence of better grades in some students.

Table 2. Comparison of means between study groups

\begin{tabular}{ccc}
\hline Groups & F & P \\
\hline $\begin{array}{c}\text { UNAMBA } \\
\text { UAP }\end{array}$ & 21.9 & $0.000^{*}$ \\
$\begin{array}{c}\text { UNAMBA } \\
\text { UTEA }\end{array}$ & 11.4 & $0.000^{*}$ \\
UAP & & \\
UTEA & 0.52 & 0.061 \\
\hline
\end{tabular}

In table 2, statistically significant differences were found in the average obtained by the students of the state university (UNAMBA) in comparison to the means obtained by the students of the other 2 universities ( $p$ $<0.05)$. On the other hand, the performance obtained by the students of the two private universities does not differ significantly $(p>0.05)$. In students of private universities, poor performance is common in relation to the variational behavior of functions, while in the state university, although the performance is still poor, it is better than in the other 2 universities.

Table 3. Percentage of correct answers on determining regions of growth and positivity

\begin{tabular}{lcccccc}
\hline \multirow{2}{*}{ Group } & \multicolumn{2}{c}{ CP } & CN & DP & DN & P \\
\cline { 2 - 6 } \multicolumn{2}{c}{ Graphic Registry (RG) } & \multicolumn{3}{c}{ Algebraic Registry (RA) } \\
\hline UNAMBA & $50.00 \%$ & $37.50 \%$ & $50.00 \%$ & $50.00 \%$ & $35.40 \%$ & $27.10 \%$ \\
UAP & $60.90 \%$ & $52.20 \%$ & $60.90 \%$ & $65.20 \%$ & $0.00 \%$ & $0.00 \%$ \\
UTEA & $48.30 \%$ & $41.40 \%$ & $48.30 \%$ & $65.50 \%$ & $3.45 \%$ & $0.00 \%$ \\
\hline
\end{tabular}

Note: $\mathrm{CP}=$ Growth and positivity, $\mathrm{CN}=$ Growth and negativity; $\mathrm{DP}=$ Decrease and positivity; $\mathrm{DN}=$ Decrease and negativity; $\mathrm{P}=$ Positivity; $\mathrm{N}$ = Negativity 
Table 3 shows that, in the three study groups, work within the graphic register proved to be more effective in terms of determining the regions of growth, decrease, positivity and negativity of a function. This reflects that a large part of the students correctly read the proposed graph and make a correct coordination between the graph and the proposed algebraic symbology as an alternative response.

Table 4. Percentage of correct answers on indicators of variational behavior

\begin{tabular}{lccrcc}
\hline \multirow{2}{*}{ Grupo } & \multirow{2}{*}{ IPE } & \multicolumn{2}{c}{ IVV } & \multirow{2}{*}{ CF } & \multirow{2}{*}{ VE } \\
\cline { 3 - 4 } & & RG & RA & & \\
\hline UNAMBA & $31.30 \%$ & $66.70 \%$ & $29.20 \%$ & $9.38 \%$ & $50.00 \%$ \\
UAP & $60.90 \%$ & $58.00 \%$ & $0.00 \%$ & $10.90 \%$ & $6.52 \%$ \\
UTEA & $62.10 \%$ & $43.70 \%$ & $0.00 \%$ & $15.50 \%$ & $6.90 \%$ \\
\hline
\end{tabular}

Note: IPE = Intervals or stability points; IVV = Variation intervals of variables $; \mathrm{CF}=$ Function behavior; $\mathrm{VE}=$ Extreme Values

Table 4 shows the evaluation of the behavior of the function, as well as the determination of extreme values constituted the variational tasks that presented the most difficulties to the students. Both tasks were raised within the graphic register, which indicates that students are not accustomed to obtaining graphical information of a variational type and that they do not perform an adequate reading of the presented graph. Similarly, the determination of intervals of variation of the variables within the algebraic register presented many difficulties that are reflected in the low percentages of correct answers, a different situation in the graphic register.

Table 5 shows the main errors found in the students' responses to the situations raised in the evaluation questionnaire.

Table 5. Some Errors found

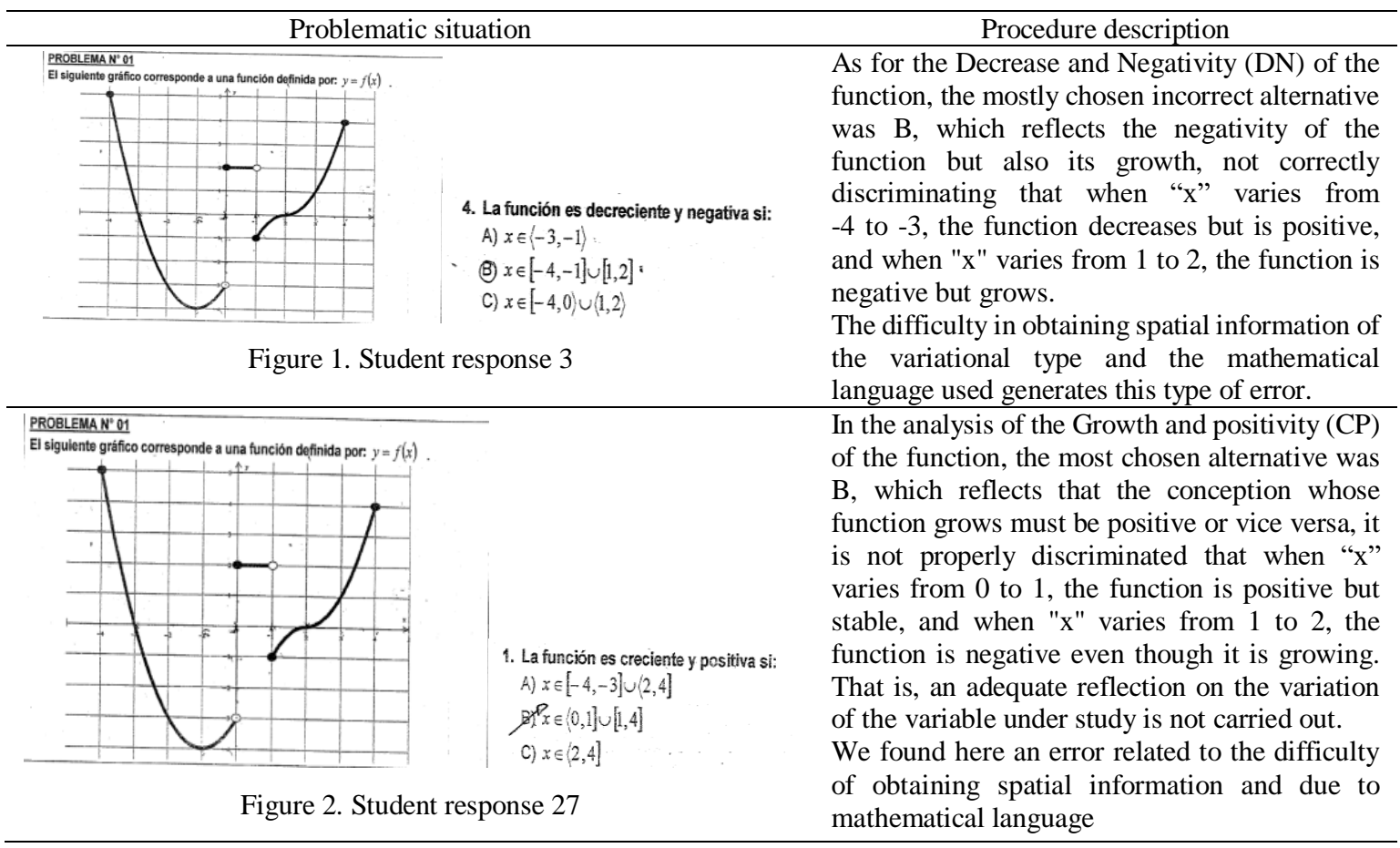




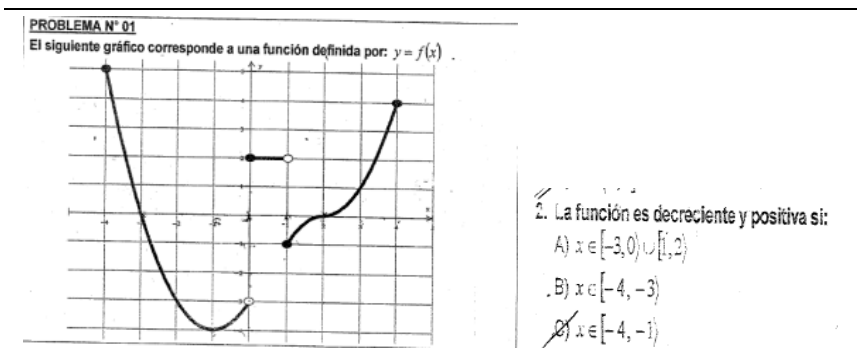

Figure 3. Student response 38
In the analysis of the Decrease and positivity (DP) of the function, a large part of the students chose alternative $\mathrm{C}$, where the function is decreasing but part of it is negative, demonstrating difficulties in correctly discriminating the location of the function within the Cartesian plane, it is not discriminated that when " $\mathrm{x}$ " varies between -3 and -1 , the function is negative. We also find here an error related to the difficulty of obtaining spatial information, not having an adequate reading of the graph from a variational perspective.

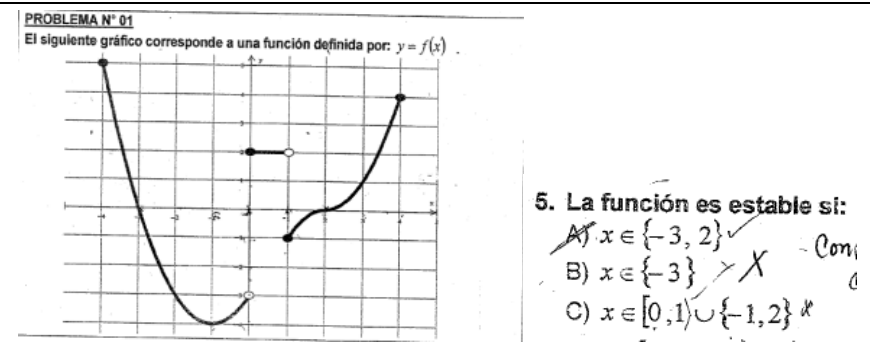

Figure 4. Student response 42

The difficulties encountered in this task refer to the confusion in students to interpret the stability of the function. Some students confuse stability of the function with nullity of the function, which led them to choose as an alternative answer the A, where the function is canceled, but does not seem to associate stability with lack of growth or decrease.

The error related to the difficulty of obtaining spatial information as well as to incorrect associations and to the erroneous construction of previous knowledge is verified

As for the work in the algebraic register, the students resorted to the tabulation strategy rather than to propose a graphic or algebraic strategy that reflects the real variation of the variable. This tabulation was performed directly without considering the form of the function that affects the variation of the requested variable, it is preferred to work the function in a timely manner and make a direct reading of the results without analyzing the form of the expression and how it determines the variation of the variable "y".

The presence of errors related to incorrect associations and to the deficiency in the construction of previous knowledge that lead to erroneous calculations is evidenced

Figure 5. Student response 49

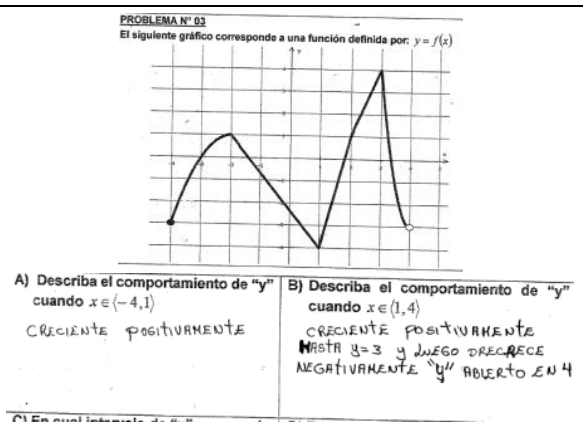

Figure 6. Student response 82

The low percentages in all groups reflect the difficulties that students have in reading the graph and outlining a correct description of the behavior of the function. The greatest difficulties arose when the students had to analyze and describe graphically how the variation of the function occurs. The foregoing highlights the problems students have in coordinating verbal registration and the graph from a variational perspective.

Errors related to mathematical language and to obtaining spatial information that generate incorrect associations are evidenced. 


\section{CONCLUSION}

The analysis of the results obtained after the application of the questionnaire reflects the existence of difficulties in students when they have to determine and describe the variational behavior of the functions represented either graphically or in algebraic or analytical form.

The students' performance turned out to be deficient in the tasks of evaluation of the variational behavior of the functions, there being no significant differences in the study groups, which reflects difficulties of didactic type as a result of the few spaces that are provided to the students within the classroom to perform tasks of variational type. The analysis of the data reported in Table 3 and Table 4, show that students prefer to work the functions in a timely manner, being able to read points or plot them, however, they do not show a real reflection on the variational behavior in intervals of the variables or globally (Bell and Janvier, 1981).

The analysis of the results reported in Table 4, reflects that students have difficulty discriminating between stationary points of a function and the zeros of the function, which indicates confusion between the behavior and the location of the function. This confusion also occurs at the moment that students have to discriminate between the growth and decrease of the function with their positivity and negativity (Dolores, 2004).

The errors that were mostly found in the procedures or responses of the students are related to mathematical language, the limitations to obtain spatial information, to establish erroneous inferences and the inadequate development of previous knowledge, which does not allow them to properly assess the variational behavior of the functions.

On the other hand, the errors found by the students are largely based on the inadequate coordination between representation records of a function, in our case, graphic, algebraic and verbal records. These cognitive difficulties do not allow for an adequate conversion from one register to the other as a result of the lack of congruence between the significant units that make up the representation records, which is consistent with that indicated by Duval (2004) and coincides with that indicated by Dolores, Chi, Canul, Cantú and Pastor (2009), who found it difficult for students to establish relationships between verbal descriptions and graphic representations.

The above also reflects that students are not accustomed to working problem situations that have variation and change as their central axis. In general, algebraic work is limited to the evaluation of a function in certain values of the variables, or to identify domains and ranges. The table of values is only used as a support resource to sketch the graph of a function, and as for the work in the graphic register, this is limited to the construction of the graph. In none of the three cases, the student is questioned about the variational behavior of the function, with which the student sees his work and reflection limited to tasks that involve algorithmic resolution strategies, losing valuable time for the discussion of variational situations, which require of the student the management and development of variational strategies. This reality, which occurs within the classroom, represents a didactic type of difficulty faced by students, and that should serve as a reflection on the part of teachers. From this, it is recommended that the design of pedagogical alternatives that seek the development of variational thinking should be developed based on the analysis of the mistakes that students make.

\section{REFERENCES}

Abrate, R. et al, 2006. Errores y dificultades en Matemática: Análisis de causas y sugerencias de trabajo. Universidad Nacional de Villa María, Buenos Aires, Argentina.

Artigue, M., 1995. La enseñanza de los principios del cálculo: problemas epistemológicos, cognitivos y didácticos. Ingeniería didáctica en educación matemática. Grupo Editorial Iberoamérica, México DF, México.

Bachelard, Cl., 1998. La formación del espíritu científico. Siglo Veintiuno Editores, México DF, México.

Bell A. and Janvier, C., 1981. The interpretation of graphs representing situations. In For de Learning of Mathematics, Vol. 2, No. 19, pp. 34-42.

Brosseau, G., 1986. Fundamentos y Métodos de la Didáctica de la Matemática. Facultad de Matemática, Astronomía y Física, Córdova, Argentina.

Cantoral, R., 2013. Desarrollo del Pensamiento y Lenguaje Variacional. Progreso S. A., México DF, México.

Carrión, V., 2007. Análisis de errores de estudiantes y profesores en expresiones combinadas con números naturales. In Unión Revista Iberoamericana de Educación Matemática, Vol. 11, pp. 19-57. 
Contreras, A. and Font, V., 2002. ¿Se puede aprender por medio de los cambios entre los sistemas de representación semiótica?. XVIII Jornadas del Seminario Interuniversitario de Investigación en didáctica de las Matemáticas (SI-IDM), Castellón, España, pp. 1-21.

Del Puerto, S. et al, 2006. Análisis de los errores: una valiosa fuente de información acerca del aprendizaje de las Matemáticas. In Revista Iberoamericana de Educación, Vol. 38, No. 4.

Dolores, C. et al, 2009. De las descripciones verbales a las representaciones gráficas. In UNION, Revista Iberoamericana de Educación Matemática, Vol. 18, pp. 41-57.

Dolores, C., 2004. Acerca del análisis de las funciones a través de sus gráficas: concepciones alternativas de estudiantes de bachillerato. In Revista Latinoamericana de Investigación en Matemática Educativa, Vol. 3, No. 7, pp. 195-208.

Dolores, C., 2007. La derivada y el Cálculo. Una mirada sobre su enseñanza por medio de los textos y programas. Ediciones Díaz de Santos, México DF, México.

Duval, R., 1998. Registros de representación semiótica y funcionamiento cognitivo del pensamiento. Grupo Editorial Iberoamérica SA, México DF, México.

Duval, R., 2004|. Semiosis y Pensamiento humano. Registros semióticos y Aprendizaje Intelectuales. Universidad del Valle., Cali, Colombia.

Engler, A. et al, 2004. Los errores en el aprendizaje de matemática. In Revista Premisa, Vol. 6, No. 23, pp. 23-32.

Farfán, R., 1992. ¿Matemática Educativa en el nivel superior? Seis años de investigación en la Reunión Centroamericana y del Caribe. En Cantoral, R., Farfán, R. M. \& Imaz, C. (Eds.). In Publicaciones Centroamericanas, Vol. 6, No. 2, pp. 236-253

González, R., 2006. La derivada como una organización de las derivadas sucesivas: Estudio de la puesta en funcionamiento de una ingeniería didáctica de resignificación. (Tesis de maestría no publicada). Centro de investigación y estudios avanzados del IPN, México D.F., México.

Vasco, C., 2006. El Pensamiento Variacional, la Modelación y las Nuevas Tecnologías. Ministerio de Educación Nacional, Bogotá, Colombia. 